\title{
Addressing the commercial determinants is critical to emerging economies
}

Economic growth in emerging economies has moved millions out of poverty. World Bank data show that some $2.8 \mathrm{bn}$ people -40 per cent of the world's population - now live on between $\$ 2$ and $\$ 10$ a day. This "fragile middle" is now the world's biggest income group. That is why they are also the target of consumer goods companies including processed food, tobacco, alcohol and sweet soft drinks - which means an exponentially expanding market of unhealthy products that shift lifestyles and contribute to the increase of non communicable disease (NCDs). Nearly four out of five deaths (80\%) from NCDs now occur in low- or middle-income countries; the rate of increase of childhood overweight and obesity has been more than $30 \%$ higher than that of developed countries. This requires rapid and determined political action by government both at home and in the international arena.

When the health ministers from Brazil, Russia, India, China and South Africa met at the end of 2014 in Brazil, they prioritized the need for action on NCDs within their countries. The impact of NCDs on their economies is staggering: the World Bank has calculated that in a single decade, developing countries are expected to lose 84 billion dollars of productivity from the death and disability caused by NCDs. Significant global agreements now exist and countries are challenged to address the determinants of NCDs through regulation in the face of significant pressure from global industries. There is still a long way to go to implement the Framework Convention on Tobacco Control FCTC and only a few countries have moved to counteract the flooding of their consumer markets with unhealthy commodities, for example through taxing products high in sugar content. The health sector lacks the power to regulate the global players; this requires a whole of government approach as well as joint action across borders.

Poor health and health shocks are leading causes of chronic poverty and impoverishment. Especially CVD and diabetes have become a leading threat to people's health in most of the emerging economies, hitting the productive younger age group in the "fragile middle". In countries with very few formal safety nets and lack of universal health coverage households often need to sell assets, use their savings or borrow at high interest rates in order to receive health care. WHO has drawn attention to the fact that 100 million fall into poverty trying to access health care. Many emerging countries have now realized that universal health coverage is critical component of economic growth, social cohesions and poverty reduction. But as governments build health systems and work on structural reforms including social protection and universal health coverage - they need to also urgently regulate unhealthy commodities in order to break the vicious cycle of disease and poverty.

The WHO Commission on the Social Determinants of Health addressed the complexity of health determinants through the concept of the social determinants of health. These are the conditions in which people are born, grow, live, work and age and they are shaped by the distribution of money, power and resources at global, national and local levels. The Rio Political Declaration on Social Determinants of Health, adopted in 2011, highlighted that it requires political commitment and momentum to address social determinants and growing inequalities in health within and between countries. But the profit driven NCD epidemic which hits the poor and the "fragile middle" hardest - requires an equal political concern for the commercial determinants of health. Emerging economies should take the lead in this area of global health because the health, social and economic consequences for their societies are staggering.

Ilona Kickbusch

Global Health Programme, The Graduate Institute, Geneva, Switzerland 